Est Ag 49 (2014) 503-523

\title{
La alegría de ser cristianos comprometidos.
}

\section{Una aproximación a la primitiva comunidad de Tesalónica ${ }^{1}$}

\author{
P. Luis Ángel Montes Peral
}

\begin{abstract}
The beautiful first Letter to the Thessalonians constitutes the first Christian writing of whose authenticity we can be sure. With good reason it can be called the "letter of that joy which comes from being a committed Christian". It truly constitutes a song of rejoicing for God's activity that made itself manifest in many ways in one of the Church's earliest communities in Europe. This leads us to a highly relevant reflection: Christianity has, since its very beginnings, been essentially linked to the joy and commitment of its belie-vers. Pope Francis is completely right when he begins his Apostolic Exhortation with the words, "The joy of the Gospel fills the hearts and lives of all who encounter Jesus." It is true. It filled the heart and life of Paul and the Thessalonians and today it can also fill our hearts and our lives, which are in such need of inner enthusiasm and convincing witness in the face of the world.
\end{abstract}

Key words: The joy of the Gospel, committed Christians, Thessalonian community, Saint Paul.

RESUMEN: La preciosa carta Primera Tesalonicenses constituye el primer escrito cristiano del que tenemos noticia cierta. Con muy buenas razones podemos denominarla como la «carta de la alegría propia del ser cristiano com-

1 Conferencia pronunciada el 8 de abril de 2014 en el marco de las tradicionales Conferencias Cuaresmales, que cada año organiza la Diócesis de Palencia en la ciudad. Haciendo referencia a la Exhortación Apostólica «Evangelii Gaudium» del Papa Francisco, esta vez llevaban por lema: «La alegría del Evangelio. El gozo de darse a los demás». Se ofrece el texto tal como fue pronunciado. 
prometido». En verdad constituye todo un canto de gozo a la actuación de Dios manifestada de muy diversas formas en una de las más primitivas comunidades en territorio europeo. Esto nos lleva a una reflexión muy pertinente: Desde sus inicios el cristianismo ha estado unido esencialmente a la alegría y al compromiso creyente. Tiene toda la razón el Papa Francisco, cuando comienza su Exhortación Apostólica con estas atinadas palabras: "La alegría del Evangelio llena el corazón y la vida entera de los que se encuentran con Cristo». Sí, llenó el corazón y la vida de Pablo y de los tesalonicenses y hoy puede llenar también nuestro corazón y nuestra propia vida, tan necesitada de entusiasmo interior y de testimonio convincente ante el mundo.

Palabras clave: La alegría del Evangelio, cristianos comprometidos, comunidad de Tesalónica, San Pablo.

\section{Introducción}

1. El Vaticano II, celebrado hace ya cincuenta años, nos hizo en su momento una apremiante invitación a volver a las fuentes, para poder conocer en hondura nuestra identidad más específica y recuperar en toda su originalidad la actuación que nos caracteriza como fieles católicos. Se trata de una de las finalidades o uno de los objetivos conciliares, que con el paso del tiempo más fecundidad ha mostrado en la vida eclesial durante este último medio siglo. Había que retomar de forma directa la lectura de la Palabra de Dios, tal como aparece en la Sagrada Escritura. Había que estudiar la Biblia, interpretarla en la manera debida y actualizarla para el hombre de hoy, convirtiéndola en el corazón mismo de nuestra espiritualidad y en el «el alma de la teología». La Palabra de Dios no sólo constituye nuestro principal alimento espiritual, también se alza como realidad primera, que orienta nuestra existencia y confiere sentido a lo que somos y hacemos.

2. El Concilio nos enseñó del mismo modo que no podíamos vivir aislados nuestra fe, como si fuéramos islas solitarias, actuando cada uno a su aire y sin conexión con los demás creyentes. Estábamos llamados a testimoniar de forma comprometida el ser cristiano en comunidad y a sentir la experiencia de la fraternidad con el gozo, que proporciona la salvación, verificada en la historia de un pueblo unido. Para ello necesitábamos superar las distintas formas de individualismo, que se han ido multiplicando en nuestra rica tradición de muchos siglos de existencia. No podía- 
mos actuar como francotiradores. Teníamos que ponernos en cálida relación con nuestros hermanos, los hombres, así como caminar juntos en la construcción de un mundo mejor y una sociedad renovada conforme al espíritu del Evangelio. No lo olvidemos nunca: Las grandes empresas humanas se realizan en solidaridad. De una manera muy especial en el cristianismo, que por vocación y misión constituye una familia de hijos y hermanos. Una comunidad, a la que sobre todo le interesa el amor y cuanto está relacionado con el amor.

3. El Concilio nos dio también muchas razones para ser cristianos alegres. Había que terminar con una religión triste, anquilosada, que nada tenía que ver con la alegría que supuso el paso de Jesús por este mundo y el anuncio gozoso de la buena noticia de la salvación. Todos conocemos el dicho castellano: Un santo triste es un triste santo. Y los padres conciliares lo sabían muy bien y quisieron que superáramos la tristeza, huyéramos de la tibieza y no cayéramos en la aburrida rutina. De hecho uno de los documentos más importantes del Vaticano II se titula: «Gaudium et Spes». Es decir, el gozo y la esperanza, con los que la Iglesia se muestra solidaria con toda la humanidad. De hecho todo lo genuinamente humano encuentra eco en su corazón gozoso. Y una de esas realidades humanas primeras y más atrayentes está precisamente en la alegría, que salta de la fe, se verifica en el amor y alienta la esperanza. La alegría se constata «en nosotros» y «con nosotros». Es receptiva, pero también activa. Ciertamente se nos proporciona como gracia a recibir con memoria agradecida y del mismo modo como tarea a realizar en el quehacer de cada día. Dicho de otro modo: Es Dios quien nos proporciona la alegría, pero también quiere que la acojamos en nuestro corazón, transparentándola ante los demás y activándola mediante el compromiso de la fe, guiado por el amor. Nada más atractivo que un cristiano alegre, que vive con entusiasmo su misión en el mundo.

\section{Primera Parte:}

\section{DESCRIPCIÓN DE LA PRIMERA CARTA A LOS TESALONICENES}

Teniendo en cuenta estos tres principios conciliares: la vuelta a la Palabra de Dios, el responsable compartir comunitario y la llamada a la alegría; principios conciliares, que una vez más han sido resaltados por el 
Papa Francisco en su Exhortación Apostólica «Evangelii Gaudium», he elegido la Primera Carta de San Pablo a los Tesalonicenses, para iluminar el hecho de cómo podemos a) ser cristianos alegres y b) vivir nuestro testimonio de fe de forma realmente comprometida, c) siguiendo las pautas de la Sagrada Escritura. La fe y el compromiso cristianos, según el sentir del Apóstol Pablo, tienen mucho que ver con la alegría. De ahí que haya titulado esta conferencia así: «La alegría de ser cristianos comprometidos». Y como subtítulo: «Una aproximación a la primitiva comunidad de Tesalónica».

\section{LA Comunidad de TeSalónica}

La Carta Primera a los Tesalonicenses tiene una especial significación para el cristianismo de todos los tiempos. Constituye el primer escrito cristiano, que forma parte de la Palabra inspirada del Segundo Testamento. Fue compuesto por nuestro autor en la primavera o verano del año 50 de nuestra era y pronto se vio en ella un tesoro, que el Espíritu regalaba a los creyentes. Nos estamos remontando entonces a tiempos muy primitivos de la primera iglesia, cuando el cristianismo se estaba gestando y dando los primeros pasos. La frescura y el júbilo de la fe se muestran palpablemente en cada una de sus páginas. Conocernos y vivir mejor nuestra religión nos lleva inexorablemente a los orígenes y en ellos a esta preciosa carta.

El Apóstol de las Gentes escribió su misiva pocos meses después de haber fundado la comunidad de Tesalónica durante uno de sus viajes apostólicos (Hch 17,1-9). Tesalónica era entonces la movida capital de la provincia romana de Macedonia, la parte norte de Grecia. Era una ciudad populosa y estaba situada, de forma privilegiada, en un cruce de caminos entre oriente y occidente. La organización tanto política como militar podía considerarse también como excelente para aquellos tiempos. Desde su fundación, tres siglos antes, había ido adquiriendo creciente importancia en el ámbito helenista.

De ahí que Pablo escogiera esta ciudad para transmitir a los paganos el Evangelio de Jesucristo. Y la verdad que no dejó de tener su éxito. Como consecuencia de su ardorosa predicación se adhirieron a la fe unas ochenta a cien personas en esa bulliciosa ciudad. Y así pudo fundar una comunidad, que ha quedado para siempre como ejemplo y referencia de lo que una auténtica comunidad viva está llamada a ser. Algunos de sus miembros provenían del judaísmo, la mayoría de los prosélitos y de la gentilidad. Según el testimonio de San Lucas entre los convertidos se 
encontraban «no pocas mujeres distinguidas» (Hch 17,4), aunque no se ha conservado ningún nombre de ellas².

Vivir la fe cristiana en medio del mundo pagano y con los vientos en contra, no era un empeño fácil. Con todo, los misioneros fundadores de la comunidad de Tesalónica, es decir Pablo y sus compañeros en la misión Silvano y Timoteo $(1,1)^{3}$, nunca perdieron el ánimo y siempre mantuvieron el arrojo en su afán evangelizador. Confesaron y anunciaron con valentía a Cristo como el Mesías de las Escrituras Santas (Hch 17,3), así acostumbraban a hacer sin ningún desmayo en su tarea. Pero casi desde el primer momento encontraron la incomprensión de la población griega y muy pronto fueron perseguidos por los judíos, que poseían en la ciudad una potente e influyente colonia (Hch 17,5ss).

Pablo y su discípulo Silvano tuvieron que salir huyendo de la ciudad (Hch 17,10), porque la situación se había convertido en muy peligrosa para ellos. Por instigación de algunos judíos poderosos, que no estaban dispuestos a reconocer a Jesús como el Cristo, estuvieron a punto de ser llevados a juicio ante las autoridades políticas y más pronto de lo deseado fueron perseguidos injustamente (Hch 17,6-9). Cuando Pablo escribe la carta, con la colaboración de sus fieles discípulos, se encuentra en el sur de Grecia, en la populosa ciudad de Corinto. En ese momento estaba especialmente preocupado por la marcha de aquella comunidad a la que el Apóstol había cogido un gran cariño, a pesar del escaso tiempo que había permanecido en ella.

\section{LA BUENA MARCHA DE LA COMUNIDAD: LA ALEGRÍA DE SER CRISTIANOS}

A través de su fiel discípulo Timoteo recibe al fin, después de un breve tiempo de incertidumbre, buenas noticias de la marcha de la comunidad recién estrenada. Se estaba desarrollando bien, creciendo en la fe y siendo testimonio para muchos. Pero a los tesalonicenses les preocupaba mucho en su existencia diaria una cuestión, que podemos calificar de crucial. En ese corto tiempo pasado algunos hermanos habían muerto y pre-

2 Sí contamos con el nombre de una cristiana de la comunidad de Filipos, la primera comunidad en el continente europeo (Hch 16,11ss), fundada por San Pablo un poco antes de la de Tesalónica. Su nombre es «Lidia, natural de Tiatira, vendedora de púrpura, que adoraba al verdadero Dios» (Hch 16,14). Se trata de la primera cristiana europea con nombre propio conocido.

3 Por razones obvias suprimo la sigla 1 Tes en todas las citas referentes a Primera Tesalonicenses. 
guntaban al Apóstol, qué suerte iban a correr los que habían fallecido antes de la venida de Jesús en gloria y majestad. Pablo escribe su carta precisamente para responder a esta pregunta y para afianzarlos en la vida cristiana, que habían acogido con tanta generosidad y que estaban desarrollando con un esfuerzo digno de todo elogio.

Podemos denominar este escrito como la «carta de la alegría propia del ser cristiano comprometido». En verdad constituye todo un canto de gozo a la actuación de Dios manifestada de muy diversas formas en la pujante comunidad de los tesalonicenses. Esto nos lleva a una reflexión muy pertinente: Desde sus inicios el cristianismo ha estado unido esencialmente a la alegría y al compromiso de la fe. Y así continúa esta unión hasta el día de hoy, siempre que con la ayuda de la gracia divina vivamos, como lo que en realidad es, ese compromiso.

\section{Tes 1,2-10}

Merece la pena leer despacio el capítulo primero, porque no tiene desperdicio y en él ya aparece resaltado con gran fuerza el gozo de los tesalonicenses, debido a la fe comprometida que estaban testimoniando ante el resto de los creyentes y en el corazón mismo de la sociedad. Mostrándose como un grupo alternativo, mantenían los rasgos específicos de una fraternidad, presidida por el Padre amoroso de los cielos, que los había elegido para un cometido entusiasmante, ponían a Jesucristo, el Hijo, en su centro y recibían la fuerza santificadora del Espíritu.

\section{LO NUCLEAR DEL CRISTIANISMO}

Resulta gratificante comprobar la genialidad religiosa de cuño cristiano, mostrada por Pablo aquí. Ya en las primeras palabras que dirige a los tesalonicenses pone de manifiesto lo que significa la experiencia gozosa de fe cristiana. Sorprendidos, además encontramos en su condensada oración de acción de gracias una selección de los temas nucleares de la espiritualidad cristiana de todos los tiempos:

- la plegaria de acción de gracias y petición (v. 2)

- la paternidad divina (v. 3);

- la puesta en práctica de las virtudes teologales (v. 3);

- la elección cristiana como iniciativa divina (v. 4);

- la fraternidad cristiana (v. 4);

- el Evangelio anunciado como Palabra de Dios y recibido con la fuerza y plenitud del Espíritu (v. 5-6); 
- la imitación de Cristo y del apóstol (v. 6);

- el gozo que proviene del Espíritu (v.6);

- el testimonio de fe en la vida cristiana como modelo a seguir y motivo de elogio (v. 7-9);

- el abandono de los ídolos (v. 9);

- la conversión al Dios vivo y verdadero (v. 9);

- la Resurrección del Hijo Jesús y la Parusía (v. 10).

En la exposición de los temas ofrecidos están integrados diversos elementos religiosos fundamentales, que no pueden faltar en la experiencia gozosa de la fe cristiana de todos los tiempos. Comprobémoslo, aunque sea a grandes trazos.

\subsection{Las Tres Personas Divinas}

Seis veces aparece el nombre de Dios (vs. 2.3.4.8.92). Pero se presenta al Altísimo con unas características muy especiales, que conviene no pasar por alto: en su íntima relación con Jesucristo nuestro Señor (vs. 3.6) y sobre todo en su función de Padre (v. 3). Se menciona en dos ocasiones al Espíritu Santo, que es el que proporciona a los creyentes fuerza y plenitud (v. 5) y de un modo muy especial les confiere alegría (v. 6). La referencia al Hijo abre y cierra la acción de gracias (vs. 3.10).

Aunque no aparecen las tres personas divinas juntas, como en otros textos posteriores, se las menciona a cada una de las tres de forma bien significativa, al principio, en medio y al final de la acción de gracias. No puede lograrse una verdadera experiencia de fe sin la presencia y actuación de la Trinidad en los creyentes. Es verdad que las enseñanzas trinitarias aparecen aquí tan sólo en su origen y formación primera. Pasarán siglos hasta que se precise de forma definitiva la identidad de cada una de las personas y la relación existente entre ellas. Pero ya están confesadas las tres personas en su especificidad: en su paternidad, filiación y expiración.

No deja de sorprender entonces, que los elementos esenciales de la realidad trinitaria ya se encuentren enunciados aquí, aunque falte la precisión exacta, imposible de ser formulada en aquel momento por razones bien obvias. En Pablo ya empieza a percibirse, incluso gestarse el hecho crucial de que no existe contradicción alguna entre la proclamación de la unicidad de Dios, la existencia de un único Dios vivo y verdadero $(1,9), \mathrm{y}$ la confesión de su trinidad de personas: Padre $(1,1.3)$, Hijo $(1,10)$ y Espíritu Santo (1,3.6). 
La decisiva actuación trinitaria resulta bien visible en la acogida por parte de los tesalonicenses de la Palabra de Dios, acompañada por la acción impulsora y transformadora del Espíritu Santo. Se trata de una manifestación de la gracia trinitaria, derramada como complacencia de elección y predilección sobre los fieles; gracia que posibilita a éstos el que acepten el evangelio paulino como verdadera Palabra de Dios; gracia que convierte a los extraños en hermanos, llamados a practicar de forma comunitaria las virtudes teologales. Se resalta además que la alegría proviene del Espíritu.

\subsection{Las tres virtudes teologales}

De hecho, lo más granado de la gracia trinitaria se resume y consuma en esas tres realidades, denominadas más tarde «virtudes teologales»: fe, amor y esperanza. En ellas culmina la oración, eficaz por estar dirigida al Padre, inspirada por el Espíritu y testimoniada por el Hijo Jesús. El medio más eficaz de que dispone la fe es la palabra espiritual, que en su momento se vuelve oración, contacto con Dios. La expresión más fuerte que proviene del amor es la fraternidad, basada en la paternidad divina, origen y fin de toda auténtica oración. En una comunidad así, desde sus comienzos atribulada, se dispara la esperanza como expectativa viva del día del Señor en un clima de plegaria y vigilancia. Concebida como una gran fiesta triunfal, la Parusía espolea los deseos creyentes para pedir a Dios su pronta llegada y para consolarse con tan feliz acontecimiento.

Casi al final de la carta San Pablo vuelve a mencionar las tres virtudes teologales e invita a sus fieles a cubrirse, para entablar el combate cristiano, con la coraza de la fe y del amor y con el casco protector de la esperanza en la salvación $(5,8)$. Antes las asechanzas del mal, que son muchas y fuertes en el mundo, no encontramos mejor antídoto que pertrecharnos con las armas de las virtudes teologales y, revestidos con ellas, entrar decididos en el combate librado contra el mal, fiados de la fuerza del Espíritu.

\subsection{Jesucristo, el Hijo}

Jesucristo, el Hijo, aparece aquí en su relación íntima tanto con el Padre como con el Espíritu Santo. Se destacan ya, aunque sea de un modo inicial, las prerrogativas centrales de la cristología posterior: 
- Vive realmente en Dios, no sólo su memoria o su reflexión, creciendo en la convicción de los creyentes su función como el autor de la salvación.

- Más allá de la historia terrena tiene ahora una forma de existencia gloriosa, una vida inmortal y escatológica, en la que estamos llamados a participar.

- Volverá un día, manifestándose desde el cielo y liberando a los creyentes para siempre de la ira que se acerca. Este es precisamente el núcleo de la esperanza.

\subsection{La actividad de la fe}

En este el corto capítulo Pablo menciona dos veces la fe. Dirigiéndose a sus destinarios, habla de la actividad (v. 3) de su fe (v. 8). La fe siempre es activa: supone, primero, acoger al mismo Dios, que se nos entrega en Jesucristo y, segundo, testimoniar esa experiencia de Dios ante los demás con obras de amor, como mostrará más tarde en Gal 5,6. Porque han hecho suya una fe con esas características, la fama de los creyentes tesalonicenses se ha extendido entre los cristianos de toda Grecia.

Además el Apóstol nos da una definición muy atinada de lo que significa esa fe para aquellos paganos, que habían abandonado los ídolos y se había convertido al auténtico Dios, al único que merecía la pena prestar un servicio incondicional $(1,9)$. La fe necesita todo un proceso de cambio de mentalidad y comportamiento, que supone, de la mano de Cristo, rechazar la divinidad de lo que no es Dios y servir con fidelidad a la divinidad de Dios; del Dios uno y único; del Dios vivo y verdadero, que para Pablo no es otro que el Padre de Nuestro Señor Jesucristo, el Hijo. Pocas veces se ha dado una definición de la fe tan contundente y exacta como ésta: abandonar los ídolos para convertirse al Dios vivo y verdadero. Vale para los creyentes de todos los tiempos, porque sigue teniendo vigencia en cualquier momento de la historia. Pienso que de una manera especial en nuestra época.

\subsection{La encrucijada paulina: entre el sufrimiento y el gozo}

En aquel momento San Pablo, que ya no era una persona joven, se encontraba en una auténtica encrucijada en su denodado empeño por extender el cristianismo a través del mundo helenista. Se debatía, como el mismo nos comunica, entre las tribulaciones y los sufrimientos, pero también entre el gozo y la esperanza. Y lo que acontecía en su misión, suce- 
día de forma bien semejante en la vida de sus hijos queridos, hechura suya como pocas, y cristianos comprometidos de aquella populosa ciudad, que ya no pasaban inadvertidos.

En el mismo centro del párrafo en cuestión ensalza a sus destinatarios porque, siguiendo el ejemplo del Señor y el suyo propio, han acogido «la Palabra de Dios en medio de una gran tribulación, con la alegría del Espíritu» $(1,6)$. La han abrazado - dirá más tarde - «no como palabra humana, sino cual es en verdad, palabra de Dios, que permanece operante» en los creyentes (2,13). Efectivamente, como sucedió al mismo Apóstol, los tesalonicenses, que formaban una pequeña pero bien trabada comunidad desde su fundación, fueron perseguidos tanto por sus compatriotas como por los judíos de la ciudad, que se oponían con todas sus fuerzas a que se diera a conocer a Jesucristo y sus enseñanzas sobre la fraternidad universal.

Pero la persecución no les podía privar de su alegría, que había crecido en ellos al recibir con entusiasmo el Evangelio. Estaban plenamente gozosos de haber abandonado la insatisfactoria existencia anterior, para volverse con todas las consecuencias al Padre de nuestro Señor Jesucristo. Se habían autentificado como un ejemplo convincente para todos los creyentes de Macedonia y Acaya (1,7). Aunque fueran maltratados de manera injusta por su entorno, nadie podía arrebatarles esa alegría íntima de ser cristianos, a la que el mismo Dios les llamaba mediante la elección de la que habían sido objeto por especial predilección divina (1,4). Les unía un empeño común: orientar el sentido de la vida de tal forma, que les llevara a un destino feliz, como nunca antes habían podido imaginarlo.

\section{Los tesalonicenses hiJos Queridos y alegres de San Pablo}

Dada la fidelidad que profesaban al Evangelio, el Apóstol se sentía especialmente unido a esta floreciente y joven comunidad, llegando a expresar ante sus miembros los sentimientos, que le salían de lo profundo del corazón: «Nos portamos -aquí implica también a sus discípulos Timoteo y Silvano, que le habían acompañado en la fundación de la comunidad y con los que remite la carta $(1,1)$ - con delicadeza entre vosotros, como una madre que cuida con cariño de sus hijos... porque os habéis ganado nuestro amor» (2,7s).

Más adelante les reitera: «sabéis perfectamente que, lo mismo que un padre con sus hijos, os animábamos y os urgíamos a llevar una vida digna de Dios, que os ha llamado a su reino y a su gloria» (2,11s). Por eso estaba 
plenamente gozoso y transmitía su gran alegría a los fieles confiados, llegándoselo a expresar de la forma más directa con unas palabras cuajadas de ternura y afecto: "Al fin y al cabo, ¿quién, sino vosotros puede ser nuestra esperanza, nuestra alegría y nuestra honrosa corona ante nuestro Señor, cuando venga? Sí, vosotros sois nuestra gloria y alegría» $(2,19 \mathrm{~s})$.

La alegría de Pablo, proveniente sin duda del hondo gozo que proporciona el Espíritu $(1,6)$, a pesar de las tribulaciones y de las penas, se vuelve inmediata y hasta explosiva: ¿¿Cómo podré agradecer a Dios suficientemente esta alegría desbordante con la que por vuestra causa me regocijo delante de mi Dios?» (3,9). Precisamente es esa desbordada explosión de júbilo, la que le hace prorrumpir en tres acciones de gracias (1,2ss; $2,13 \mathrm{ss} ; 3,9 \mathrm{ss})$, hecho singular, que no se vuelve a repetir en sus escritos. Exhorta una vez más a los suyos a que no cesen de estar gozosos $(5,16)$, ya que ellos son «mi gloria y mi alegría» $(2,20)$. Merece la pena entonces vivir el gozo de ser creyentes con las mismas actitudes del Apóstol.

Como podemos comprobar, San Pablo se encuentra aquí lleno de satisfacción interior, reflejada también en el exterior, cuando escribe con tanto entusiasmo y sinceridad. Y ese estado de ánimo tan positivo, que brota de la honda caridad pastoral que le quema por dentro, se lo transmite a sus queridos tesalonicenses. En ellos también a cada uno de nosotros, cuando leemos su carta y comprobamos sorprendidos la sinceridad de su entusiasmo y la fuerza contagiosa de su gozo. Pocas veces expresa su estado de ánimo jubiloso con tanta convicción como aquí. En dos ocasiones seguidas repite la palabra que más le sale de los labios y llena su corazón: alegría.

\section{LA FIRME ALEGRíA DE LA ESPERANZA}

La alegría paulina echa sus raíces en el encuentro íntimo con Jesús y en la activa participación de su muerte y resurrección. Desde su conversión en el camino de Damasco Pablo vivía ya resucitado en Cristo. La aparición del Resucitado, fruto de la gracia, le hizo reactivar una existencia nueva, distinta a la tenida hasta entonces. En las Cartas a los Gálatas y a los Filipenses expresará pensamientos y sentimientos, que nos hablan de una unión íntima con Cristo, que ha transformado por completo todo su ser y quehacer en este mundo. Pero no queremos presentar ahora lo que es resultado de sus escritos posteriores. Baste con atenernos a lo que expresa aquí, que tiene también una gran significación. Estaba plenamente convencido de que, llegado el momento, resucitaría como su Señor a una vida gloriosa, lo mismo que los que ya habían muerto en el Señor, 
entre los que se encontraban algunos tesalonicenses. Para que no se afligieran como los que carecían de esperanza $(4,13)$, confía a sus íntimos un secreto que ha recibido de la revelación $(4,15-18)$ :

«Esto os decimos apoyados en la Palabra del Señor.... el mismo Señor, a la voz del arcángel y al son de la trompeta, descenderá del cielo, y los muertos en Cristo resucitarán en primer lugar; después nosotros, los que vivamos, los que quedemos, seremos llevados con ellos entre las nubes al encuentro del Señor, por los aires. Y así estaremos siempre con el Señor. Consolaos, pues, mutuamente con estas palabras».

Dejando a un lado temas bien interesantes, como la firme creencia de que la Parusía tendría lugar en su propia generación, el Apóstol, llevado por la urgencia de su solicitud pastoral, contesta a la pregunta formulada por los suyos sobre la suerte de los muertos con un arranque de gozoso entusiasmado, que va más allá de las cosas de este mundo. Usando un lenguaje figurado, que no resulta difícil explicar cuando se tienen las claves de interpretación, propias de la literatura apocalíptica, transmite a los suyos el mensaje central de la esperanza cristiana, que inunda su vida de gozo y que los tesalonicenses antes no sabían descifrar, pero ansiaban conocer.

El Apóstol quiere que los suyos participen de este mismo sentimiento de gozo mediante la acogida de su propio convencimiento existencial y testimonial: existe la resurrección de los muertos y la vida eterna, adquiridas por Cristo muerto y resucitado. Y en la hora final todos experimentaremos la existencia plena de forma definitiva. El ser humano, por lo tanto, no es una pasión inútil, que acaba en la nada, un ser desgraciado que termina en la desdichada muerte, sino que cada persona está llamada a ser feliz para siempre en la presencia y cercanía del Padre mediante la unión íntima con el Hijo humanado por gracia y amor del Espíritu, que se derrama en los corazones de los bienaventurados.

Los cristianos primitivos, seguro que también los tesalonicenses, por lo que conocemos en una carta posterior, recibieron con gozo la enseñanza paulina y mostraron este firme y esperanzado convencimiento con un grito de júbilo, conservado en la misma lengua que usó Jesús, el arameo: «Maranatá». Esta palabra, compuesta de un deseo ardiente y una exclamación jubilosa, significa «ven, Señor Jesús» y expresa el gozo entusiasta de que la venida de Cristo en gloria y majestad iba a cambiar para bien su destino y les iba a situar eternamente en la bienaventuranza final. La expresión original adquiere tal importancia en el cristianismo primitivo, que aparece al final de una de las cartas paulinas (1 Cor 16,22) y la volve- 
mos a encontrar, traducida al griego, al concluir la revelación del Nuevo Testamento (Ap 22,20).

Para los creyentes existen dos palabras bien sagradas y trabadas, provenientes del arameo, «Abba» «Maranatá». Las dos están estrechamente entrelazadas. En la primera invocamos al Padre. En la segunda al Hijo humanado, el Señor Jesucristo, que vendrá en su día para renovar y plenificar todas las cosas. Y las dos palabras vienen cerradas por otra palabra aramea, que podemos poner en relación con el Espíritu: «Amén», que significa: así sea. Que se haga en nosotros realidad el amor del Padre y la salvación del Hijo con la fuerza del Espíritu. Esto es lo que quieren y transmiten para cada uno.

\section{Segunda Parte:}

\section{LOS CRISTIANOS DE TESALÓNICA Y LOS CRISTIANOS DE HOY}

¿Qué podemos aprender de los tesalonicenses hoy los cristianos? ¡Mucho y bueno! Me voy a reducir tan sólo a proponer aquí media docena de realidades creyentes fundamentales, formuladas en forma de breves tesis o proposiciones.

\section{El cristianismo es alegría en el Padre, en el Hijo y en el Esí- RITU: CONSISTE EN VIVIR EL GOZO DE LA FE COMPROMETIDA DESDE LA Trinidad SANTA}

Hemos visto cómo, a pesar de pasar por momentos bien difíciles, Pablo está alegre e invita a los tesalonicenses a la alegría. Nadie puede arrebatarles la satisfacción de ser hijos amados del Padre. A través de ellos nos está invitando a nosotros. ¡No dejéis arrebataros la alegría! ¡Estad siempre alegres! Así se lo dice con gran pasión a sus fieles de la primera hora y en ellos nos lo está confiando también a cada uno de nosotros, que vivimos ya en el siglo XXI. La razón principal por la que nos invita a la alegría consiste en que tenemos a Dios de nuestra parte. Camina con nosotros como lo hace un padre con sus hijos. Nos alienta sin descanso con el Evangelio de su Hijo y nos conforta con su Espíritu del amor y gozo.

Nuestra alegría será tanto mayor cuanto más dejemos a un lado a los ídolos, que ahora en este momento pueden ser las ansias de tener en sus 
diversas formas, de sobresalir por encima de los demás con un poder injusto y de conformar la existencia de acuerdo con el capricho y al propio gusto. El Dios vivo y verdadero nos llama a la vida y a la verdad, pero también a la austeridad y a la responsabilidad ante los demás. Nos llama, sí, a una vida y una verdad con mayúsculas. La verdadera alegría consiste, por lo tanto, en deshacerse de cuanto nos quita la libertad y nos priva de la alegría, para volvernos a la Trinidad Santa: al Padre, al Hijo y al Espíritu, que nos proporcionan el gozo y la paz de la salvación.

¡Qué alegría tan grande contar con la certeza de que el Padre del Jesucristo está vuelto hacia nosotros! ¡Qué delicia experimentar que nos ama incondicionalmente y regala a cada uno la inmensidad de su amor generoso y gratificante! ¡Qué gozo tan grande poder acoger de forma agradecida la salvación del Hijo humanado, que por nosotros murió y resucitó y, llegado el momento, nos librará de la ira venidera! ¡Qué satisfacción la que nos proporciona el Espíritu, que inhabita nuestro interior y nos ayuda a corresponder al gran amor que el Padre y el Hijo tienen a la humanidad entera y a los creyentes en particular!

\section{El CRISTIANISMo ES FRATERNIDAD: CONSISTE EN VIVIR EL GOZO QUE PROPORCIONA LA UNIÓN Y LA CONCORDIA ENTRE LOS HERMANOS}

La experiencia de fe cristiana tiene una dimensión personal, pero se realiza siempre en un contexto comunitario, en el corazón mismo de una comunidad bien dispuesta, que se abre de forma incondicional a los hermanos y al mundo exterior. Así se lo hace ver Pablo a los tesalonicenses y en ellos a cada uno de nosotros. Se trata de una experiencia fundamental e insustituible para construir la fe en lo que tiene de más básico, hondo y perenne. Todo lo valioso en nuestra vida lo construimos en compañía de los otros y ante la presencia de la Trinidad, que impulsa nuestro amor.

A lo largo de la carta aparece con insistencia un pensamiento, que proviene como consecuencia de esa experiencia de fe adquirida por los tesalonicenses durante la actuación apostólica de Pablo: Dios Padre es quien anuda, mediante los lazos luminosos del amor, las relaciones fraternales entre los distintos miembros de la comunidad (4,9). Nada menos que en catorce ocasiones llama Pablo a sus fieles hermanos $(1,4 ; 2,1.14 .17 ; 3,7$; $4,1.10 .13 ; 5,1.4 \cdot 12.25 .26 .27)$. Merece la pena meditar cada uno de los pasajes. No deja de ser altamente consolador que en el primer escrito cristiano aparezca más de una docena de veces el calificativo de hermanos para 
designar a los miembros de la comunidad, tanto mujeres como hombres, sin distinción de posición.

La fraternidad se legitima así como uno de los componentes esenciales de la experiencia de fe cristiana. Si algo es el cristianismo es fraternidad, familia de hijos y hermanos. El amor fraterno, aceptado con gozo mediante la obediencia de la fe, constituye además el principio de la unidad y del orden en la comunidad. Dios mismo, como auténtico maestro de la vida interior, es quien enseña a los fieles en su corazón lo que significa en concreto amar y jamar como hijos y como hermanos! para así ir creciendo en la santidad propia del reino. Precisamente el amor fraterno es lo primero que Dios infunde a los fieles en su corazón, que se deduce del testimonio eficaz de Jesucristo y del Apóstol.

\section{EN EL CRISTIANISMO ALEGRÍA Y ORACIÓN VAN UNIDAS Y CAMINAN JUN- TAS}

Como en ninguna otra carta, la oración recorre de principio a fin toda la disertación paulina. Reza por los tesalonicenses $(1,2)$ y les ruega que también ellos recen por él $(5,25)$. Insiste que no cesen de orar (cf. Fil 4,6). No nos tiene que extrañar que en el estado de alegría en que se encuentra el Apóstol, brote de su alma la plegaria en sus distintas formas y con una fuerza inusitada. En realidad, lo hemos indicado anteriormente, nuestro escrito constituye la única carta que tiene tres sentidas acciones de gracias a Dios (1,2ss; 2,13ss; 3,9ss).

Cuando ya se está despidiendo, San Pablo inculca a los tesalonicenses con vehemencia y por última vez: «Estad siempre alegres. Sed constantes en orar» (5,16s). En Fil 4,4 reduplicará la exhortación: «Alegraos siempre en el Señor; os lo repito, alegraos». La alegría tiene que estar presente de forma permanente en sus vidas, ya que Dios no les abandona, se encuentra en medio de ellos y están llamados a compartir un destino gozoso, que no tendrá fin y consumará para siempre sus deseos de felicidad. Lo mismo nos puede decir hoy a cada uno de nosotros, llamados a integrar nuestras respectivas comunidades.

Pero la verdadera alegría va unida íntimamente a la oración, que consiste en mantenerse en constante acción de gracias, porque Dios es grande con nosotros y nos llama a una vida plenificada que no pasa, semejante a la suya. La auténtica oración hace consciente al orante de que lo mismo que Dios es feliz, también lo es él ahora y lo será para siempre en 
una existencia renovada, en la que Dios enjugará nuestras lágrimas y ya «no habrá muerte, ni duelo, ni llanto, ni dolor» (Ap 20,4).

No lo olvidemos nunca. La raíz de la alegría interior está en la oración, es decir en el encuentro directo, sencillo y humilde con el Padre, reconociéndolo en su papel de Padre y gozándonos como hijos suyos, que somos objeto de su amor condescendiente, complaciente y benevolente. Invocar la Padre bajo la acción del Espíritu desde la experiencia gratuita de los mismos sentimientos mostrados por el Hijo constituye la forma más alta de entenderse uno mismo como hijo. Además significa también estar en camino para el diálogo con su persona entrañable, que tanto bien nos proporciona cada momento de nuestra vida, cuando lo hacemos en compañía de los hermanos.

\section{NO PUEDE HABER VERDADERO CRISTIANISMO SIN EL COMPROMISO GO- ZOSO DEL AMOR}

La fe nos lleva al testimonio del amor de una manera muy especial con los hermanos. Vivir en compañía de los hermanos bajo la mirada complaciente del Padre, proporciona una gran alegría, una satisfacción existencial, que no pueden transmitirnos los poderes de este mundo. Todo cuanto nos indica Pablo en torno a la alegría y al compromiso en esta preciosa carta, lo podemos resumir con sus propias palabras en estas reflexiones, cargadas de profunda cordialidad:

« ¿Cómo podremos dar gracias a Dios por vosotros, por tanta alegría como gozamos delante de Dios por causa vuestra?... Que Dios nuestro Padre y nuestro Señor Jesús nos allanen el camino para ir a vosotros. En cuanto a vosotros que el Señor os colme y os haga rebosar de amor mutuo y de amor a todos, lo mismo que nosotros os amamos a vosotros; y que afiance así vuestros corazones, de modo que os presentéis ante Dios, nuestro Padre, santos e irreprochables en la venida de nuestro Señor Jesús con todos los santos» (3,9. 11-13).

Ante la presencia divina el Apóstol está lleno de una alegría intensa y da gracias al Padre por las maravillas que está obrando en la vida comunitaria de los tesalonicenses, a los que desea ver cuanto antes. Y la mayor de esas maravillas consiste en que están llamados a rebosar de amor, amor hacia Dios y el Señor Jesús, amor también hacia él mismo y hacia los demás; en definitiva amor a todos y en todo. Desde la fundación de la comunidad sus queridos hijos han sentido en sus personas una doble experiencia de amor generoso: la que viene directamente del Padre de los 
cielos y la que llega hasta ellos por mediación de Jesucristo y del ministerio del mismo Apóstol.

En realidad lo mucho que Dios los quiere se muestra en el gran amor que les ha manifestado el Señor y también en la predilección que San Pablo les ha profesado desde el momento que los conoció. Constantemente da pruebas de ello con sus desvelos y su solicitud, para que perseveren en su fe por Cristo. Si ellos ahora aman en la forma que lo hacen, es debido al hecho de que antes se han sentido amados por el Padre, su Hijo Jesucristo y por el Apóstol, servidor incansable del Evangelio. Lo que llena a Pablo de alegría consiste en que está situando a sus queridos fieles en el ámbito del amor del Padre y del Hijo y de esta manera les está ayudando a caminar hacia la santidad de los hijos de Dios, viviendo de la gracia divina y dándose a los demás.

Alcanzar la madurez cristiana, como consagrados a Jesús, el Señor $(4,3)$ y como testigos del Evangelio (1,5), consiste en imitar a Dios en su amor, que nos llena de satisfacción y de un gozo inefable, incapaces así de conformarnos con las cosas de este mundo. La verdadera alegría sólo puede brotar del amor de Dios y del gozo de amarnos los unos a los otros, porque el mismo Señor nos colma y nos hace rebosar con su propio amor, lleno de cariño, ternura y misericordia. Alegría, oración y amor caminan unidos en la expresión de la felicidad cristiana. No hay vida creyente de verdad sin el compromiso del amor acogido y volcado de manera responsable hacia los demás. Hecho tan gratificante les lleva a configurar una «vida digna de Dios» $(2,11)$.

La fuerza superior de acción propia de la existencia cristiana radica en el amor en la doble dimensión testimoniada y enseñada por el Hijo: amor al Padre y amor a los hermanos. Nadie puede superar esta fuerza, nadie puede sustituirla y mucho menos vencerla. Ya que tiene su origen en Dios y hace rebosar el corazón del hombre como creatura divina. Todo lo que lleva a la plenitud viene sin duda cohesionado por la grandeza y fortaleza del amor trinitario. La plenitud de los hijos del reino sólo puede venir en el encuentro con el amor procedente de Dios, que hace fuertes a los hombres. No enriquecen los bienes de este mundo, la prepotencia ante los demás, sólo el amor divino hace a los creyentes ricos en la fe y firmes en la esperanza.

La experiencia gozosa de una fe comprometida está en el hondón de la carta, debido a la acción amorosa divina manifestada en la comunidad, y al hecho de que los tesalonicenses han hecho suya esa acción con fidelidad cristiana, como buena noticia que inunda de alegría su vida y lleva al 
compromiso. Se congratula con ellos, porque progresan en el amor mutuo y en la ayuda desinteresada hacia los otros como testigos fuertes del Evangelio, haciéndose imitadores de lo que Dios hace por cada hombre. Esa praxis en el amor hacia los demás les hace irreprochables y les encamina hacia la santidad de los hijos y hermanos del reino, que en su día llegará a la plenitud.

\section{LA CONCRECIÓN DEL AMOR FRATERNO}

El amor de verdad huye de la abstracción, siempre es concreto y se expresa a través del cuerpo irreprochable, en comunión con el alma y el espíritu (5,23). Para realizarlo bien, precisamos de manera insoslayable el concurso de la propia corporeidad, irreprochable en sus acciones y bien dispuesta hacia los demás. Estar decididos a no pervertir la oblación del amor con acciones impropias de los auténticos creyentes, constituye la condición necesaria para situarse en la verdadera actitud de amar.

De ahí que el Apóstol, al iniciar la parte parenética de su argumentación, haga un encendido y denso elogio de la castidad (4,1-8). En dos ocasiones recalca, que corresponde a la voluntad divina vivir como consagrados, apartándose de las pasiones bajas, como hacen los gentiles (4,3s). «Dios no nos ha llamado a una vida impura, sino santa» $(4,7)$. En una sociedad acostumbrada al adulterio, en la que no había ningún respeto por la mujer del prójimo, el Apóstol inculca a los suyos a que «nadie pase por encima de su hermano, ni se aproveche con engaño» $(4,6)$.

La base del auténtico amor fraterno $(4,9)$ y del progreso en él $(4,11)$ consiste en disponer el cuerpo de tal forma, que podamos entregarnos a los demás mediante la práctica de una ayuda limpia y de un apoyo generoso, fuera de las trabas del egoísmo que se encierra en el propio provecho y no sabe compartir los bienes con los demás. Apoyarse mutuamente en la bondad, arriesgarse por los otros, compartir cuanto se es y se tiene representan sin duda caminos seguros en el intento de realizarse en el amor fraterno, que tanto agrada a Dios y tanto bien hace a los hombres.

En dos ocasiones invita a los suyos a vivir en sobriedad $(5,6.8)$ y dejar a un lado las borracheras $(5,7)$, que apartan de la auténtica alegría, aunque camuflen la insatisfacción. Esta sobriedad resulta especialmente importante hoy, para estar atento a las necesidades de los demás y socorrer a los menesterosos allí donde precisan de nuestra ayuda y nosotros podemos salir al paso de sus penurias con eficacia. Practicar así el amor fraterno significa tanto como vivir de forma alternativa el ser «hijos de la luz e 
hijos del día» $(5,5)$ en medio de las tinieblas del mundo. Cuerpo, alma y espíritu, unidos en la correspondiente armonía han de estar conjuntados en la praxis del amor, manteniéndose cada uno «sin reproche hasta la venida de nuestro Señor Jesucristo» $(5,23)$.

La alegría prende así en el compromiso moral. Y el compromiso moral salta en la alegría. La reciprocidad existente entre alegría y compromiso no puede ser más fecunda y satisfactoria en la vivencia concreta del amor fraterno. No cabe la menor duda que darse a los demás aumenta en los creyentes la capacidad de alegrarse, de modo que la comunidad puede convertirse en la familia de la alegría, que supera la tristeza del egoísmo y lleva al júbilo de la salvación recibida y compartida.

\section{El CRistianismo está llamado a dar Razón de la ALEGRe espe- RANZA}

Pablo recuerda el acontecimiento de la Parusía del Señor, tema central del escrito, repetidamente $(2,19 ; 3,13 ; 5,2.23)$ y en $4,13-18$, avanzada ya la carta, es descrita con tal lujo de detalles apocalípticos, que no encontramos un texto semejante en ningún otro lugar de sus escritos, tampoco en la literatura del Segundo Testamento. De hecho la Parusía, plenificación de la Resurrección de Cristo, constituye también la culminación de la existencia humana, personal y comunitariamente considerada.

Y así se la relaciona estrechamente con la resurrección de los muertos, de modo que el hombre no está abocado a la nada, sino a la felicidad perfecta. Su futuro absoluto no consiste en convertirse en cenizas y polvo. Mediante la resurrección de Cristo tiene garantizada la victoria gozosa y el triunfo esplendoroso. En la muerte prende la auténtica vida, de modo que el creyente está destinado a resucitar y a estar junto al Señor, cuando acontezca su venida, compartiendo para siempre su misma vida de Resucitado. Vida en Cristo, con Cristo y por Cristo, que se convertirá en un canto interminable de alabanza y en una experiencia creciente de felicidad.

Más que nunca los creyente actuales, siguiendo a Pablo y a los tesalonicenses, estamos llamado a dar razón de nuestra esperanza en un mundo, que rechaza lo que vaya más allá de lo que le dictan los sentidos físicos y conforma la propia existencia de cada día lejos de los valores trascendentes. Estamos llamados, sí, a testimoniar de forma convincente con hechos y palabras, que creemos en la vida eterna y esperamos la resurrección de los muertos, tal como lo confesamos cada semana en el Credo. Y 
que esa honda convicción, hecha experiencia existencial, orienta el sentido de nuestra vida y nos carga de razones para vivir con una alegría capaz de contagiar a los demás.

\section{Desenlace final}

Podemos resumir lo expuesto aquí de este modo: Este escrito, más pastoral que doctrinal, pretende llegar al corazón de unos creyentes recién convertidos, que como prueba de su autenticidad estaban siendo perseguidos, sobre todo por los judíos (2,13-16). Pablo, que tuvo que escapar de Tesalónica precipitadamente y de noche (Hch 17,4-17) y no le quedó otro remedio que dejar la comunidad sin poder concluir en ella su actividad misionera, comprueba con júbilo y asombro desde Corinto que los tesalonicenses perseveran en la fe y se muestran sensibles a la acción sobrenatural, derrochada sobre ellos de manera especialmente intensa.

El Apóstol los alienta, como un padre hace con sus hijos (2,11s), para que permanezcan en una fe firme, pero también amenazada por la adversidad. Es más, en medio de congojas y tribulaciones, les transmite ánimo y llega a expresar con toda sinceridad que se siente reconfortado por su modo de proceder, ya que a pesar de las dificultades se mantienen fieles al Señor $(3,8)$. De hecho están perseverando en el Evangelio recibido, por lo que abundan los momentos de gozo en la escritura de la carta $(2,20 ; 3,9$; $5,16)$. La insistencia en la fe, que permite esforzarse por alcanzar la madurez cristiana, sorprende de verdad. La fe testimoniada resulta del todo imprescindible para agradar a Dios Trinidad y para progresar en la espiritualidad. Además proporciona un hondo motivo de alegría en la existencia creyente.

La misiva del Apóstol constituye una decidida exhortación de consuelo a los suyos $(4,18)$, para que no pierdan la esperanza, ya que dudaban de la suerte que correspondía a los muertos $(4,1)$. Al mismo tiempo se acredita también como una exposición convincente de las verdades centrales de la fe, dirigida a unos cristianos primerizos, con los que se congratula, pero que podían caer en la tentación de abandonar su fe, ya que su vivencia cristiana no venía sostenida por un consecuente comportamiento moral $(4,3.5)$ y social $(4,9-12)$ anterior. Representa una tarea esencial de la fe transmitida con gran esfuerzo, el realizarse en la entrega a los demás y en el amor mutuo, reflejado del amor de Dios. Verter en el contexto cultural de su pensamiento griego la fe cristiana y forjar en los comportamientos de los tesalonicenses una ética comprometida, plenificada 
en el compromiso del amor, le fue más fácil de lo esperado, a pesar de la dificultad inicial de tamaña empresa. Y todo debido a que Dios estaba con él y que su palabra era recibida como Palabra divina, acompañada de la fuerza y plenitud del Espíritu (1,5).

Es de notar como se merece, que el primer documento cristiano canta, de forma singular y ascendente, el gozo del Evangelio y la alegría de la salvación, que proporciona el anuncio de la buena noticia referente a la Palabra de Dios. Pablo no cesa de invitar a los suyos a alegrarse en el Señor a lo largo y ancho de sus reflexiones. Además une ostensiblemente el alegre entusiasmo con la oración, fuertemente resaltada tanto en el ministerio del Apóstol como en el actuar de los creyentes. Tiene toda la razón el Papa Francisco, cuando comienza la ya mencionada Exhortación Apostólica con estas preciosas palabras: «La alegría del Evangelio llena el corazón y la vida entera de los que se encuentran con Cristo». Sí, llenó el corazón y la vida de Pablo y de los tesalonicenses y hoy puede llenar también nuestro corazón y nuestra propia vida, tan necesitada de gozo interior y satisfacción testimoniada al exterior. Se trata de una alegría que se renueva constantemente y se nos comunica cada día por la acción de Dios, la salvación de Jesucristo y la gracia del Espíritu del Padre y del Hijo. La alegría cristiana consiste en experimentar la fuerza transformadora del amor del Padre, que elige, de la salvación del Hijo humanado, que salva y de la santificación del Espíritu Santo, que alienta nuestra existencia hacia la plenitud con el gozo de la fe, la alegría de la esperanza y el entusiasmo del amor. 